\title{
The Impact of Position Competence on Work Happiness about Service Personnel Based on Psychological and Organizational Factors
}

\author{
Yanhua Diao ${ }^{1}$ \\ ${ }^{1}$ School of Economics and Management, Shandong Youth University of Political Science, Shandong Jinan, China \\ Correspondence: Yanhua Diao, School of Economics and Management, Shandong Youth University of Political \\ Science, Jinan, China. E-mail: 99581735@qq.com
}

Received: June 29, 2020

Accepted: August 5, 2020

Online Published: August 16, 2020

doi:10.5539/ijbm.v15n9p139

URL: https://doi.org/10.5539/ijbm.v15n9p139

\begin{abstract}
The more capable a person is, the happier he/she is at work? Our consciousness and previous relevant studies seem to agree with this view. But why in reality, many competent people are unhappy at work, complaining and leaving their jobs? What are the psychological or organizational factors that contribute to this? This article uses 328 service supervisor-employees matching questionnaires as a sample to verify the mechanism of position competence and work happiness from the mediating effect of psychological ownership (psychological perspective) and the moderating effect of POS (organizational perspective). The research result showed position competence significant impact work happiness, and psychological ownership variable plays a significant intermediary role in their relationship; Position competence positively affect their psychological ownership; psychological ownership positively affect work happiness, and perceived organizational support negatively moderates the relationship. The research results provide important theoretical support for managers to improve employees' psychological ownership to enhance their work happiness, and provide new ideas to improve organizational support to retain and make good use of talents.
\end{abstract}

Keywords: work happiness, position competence, psychological ownership, perceived organizational support

\section{Introduction}

Will he/she be happier when a person's ability is stronger? Why do many high-ability people in reality are unhappy at work, complain and leave their jobs? What factors impact on it? Whether they are scholars in the field of management and psychology, or practitioners involved in business management, they are all exploring how to improve the psychological state of employees to improve their work happiness. At the same time, in the field of human resource management, Position competence has attracted much attention since it was proposed in the 1960s. In recent years, Position competence has been given more and more important status. Many enterprises in various countries have introduced Position competence model into management and recruitment practice. Previous studies have shown that high competency can help employees experience work achievements, keep a happy mood and feel professional happiness, thus promoting work development (Wang et al., 2017; Zhu et al., 2014). Therefore, when the professional factor of competency becomes the main factor affecting the happiness of employees, it becomes very necessary to study the relationship between them.

According to the statistical bulletin on the development of human resources and social security in 2018, China's employment reached 775.86 million by the end of 2018. The service industry personnel account for $46.3 \%$ of the national employment, or about 359.22 million people, which is a large group, and the research on this group is of great significance. Therefore, this research tries to explore the impact of the service personnel' Position competence on work happiness.

\section{Review of Literature}

\subsection{Position Competence}

According to this study, Position competence is a personal characteristic that can distinguish the performance of different people. The most representative model is the personnel competency model proposed by Spencer (1993), including 11 items such as interpersonal insight and influence, etc.; in addition, Crosby et al. (1990) proposed a sense of identity, interpersonal relationships, sale skills and abilities that have significant impact on job performance, and built a competency model; Sandberg (2000) also studied the competence of computer 
personnel and built a competency model for this group. Because the survey respondents are Chinese service industry employees, the foreign scholars' indicators have been improved in design of indicators. Drawing on point of view about Zhu et al. (2014), the service industry personnel competency model has been initially established, which divided the Position competence into three indicators as work insight, work communication skills and work service ability.

In the existing research, there are many studies working on relevant work variables that may be affected by the Position competence as the independent variable, many of which explore the relationship between Position competence and career success (Kuijpers \& Scheerens, 2006; Park, 2015). These studies have drawn a more consistent conclusion that Position competence has significantly and positively affected the subjective professional success of employees' subjective satisfaction, and also affected the employees' salary, position and other objective career success. However, there are few researches working on the ways in which Position competence affects job satisfaction, and it remains to be further studied.

\subsection{Psychological Ownership}

The psychological ownership is a psychological feeling, a mental state that feeling of something is mine. It is first proposed by Pierce et al. (1991) and conceptually defined. Parker et al. (1997) emphasized that psychological ownership is a "responsibility" to something. However, Pierce et al. (2001) argued that psychological ownership is not equal to responsibility, and the core attribute of psychological ownership is possession. Beggan (1992) believed that the possession of psychological ownership also plays a significant role in the generation of individual pleasure. Pierce, Kostova and Dirks (2003) agreed that psychological ownership is divided into emotional and cognitive states. The psychological ownership discussed in this research refers to "a kind of state", that is, personal feelings about possessing a target object. The fundamental difference between psychological ownership and other psychological states lies in the relation between self and target.

The empirical research on psychological ownership is also very rich, which mainly involves its influencing factors and the dependent variables that may affect it. Pierce et al. (2009) explored the effects of five characteristics of the Job Characteristics Model (JCM) on psychological ownership. Melissa and Mayhew (2007) validated the positive impact of psychological ownership on job satisfaction. Avey (2009) validated the relationship between psychological ownership and employee retention is positively. Pan et al. (2012) verified the positive correlation between psychological ownership and positive organizational behavior. In addition, scholars have some different opinions on the relationship between psychological ownership and job performance. Pierce et al. (1991) argued that psychological ownership is positively correlated with job performance, while Dyne and Pierce (2004) argue that there is no significant correlation between them. Wagner et al. (2010) argued that when discussing the relationship between job performance and psychological ownership, the behavior within the role should be distinguished from the behavior outside the role, otherwise the prediction results will be unstable. Pierce (2001) found through empirical research that the impact about psychological ownership on job performance is related to its intensity.

In summary, there is still a large research space in the field of disagreement on psychological ownership, and this paper will study its mediating role.

\subsection{Work Happiness}

The research on happiness was divide into SWB (subjective well-being) and PWB (psychological well-being). Diener (2000) proposed that work happiness is the positive emotion of employees in their work and positive evaluation of work. The work happiness discussed in this research refers to the performance during work. It is the positive or negative feelings or emotions evoked by the realization degree and satisfaction degree of self-development, self-growth, interpersonal relationship and so on, which are offered by the organization they belong to. The work happiness in this research include 5 dimensions.

In the measurement of happiness, the most commonly used methods are extrinsic measurement and questionnaire. Questionnaire scale is the most important research tool used by current researchers to quantify happiness. The scale of happiness is also varied. This study mainly used the psychological well-being (PWB) scale (Abbott et al., 2006).

\subsection{Perceived Organizational Support}

Eisenberger et al. (1986) first put forward the concept about perceived organizational support (POS). This study believe that POS is an employee's perception of whether the organization values their rights and contributions. In addition, a questionnaire on POS was designed by Eisenberger et al. (1986), which was used for reference in this study. 
It should be noted that most studies directly discuss the relationship between outcome variables and POS, or use perceived organizational support as an intermediary variable, but there is little research on the moderating effect of POS. It is very important to understand the mechanism of organizational support. It helps managers clearly understand "why" and thus better know "how" to do it. Perceived organizational support attracts the attention of organizational managers and scholars because it can analyze the perspectives, needs and motivations of effective incentives of employees, discover and understand their needs, stimulate the behaviors of the organization to meet their needs. It is also a consideration in this study.

\section{Methodology}

\subsection{Research Hypotheses}

There are some studies about the relationship among position competence, psychological ownership, perceived organizational support and work happiness. Abraido (1997) once suggested that position ability is important in work happiness. Position competence can make personnel positive behaviors for the organization, such as improve work happiness in the organization (Tomietto et al., 2019). Based on previous studies, this study proposes the hypothesis:

H1: The position competence of service staff will positively affect their work happiness.

There are many empirical studies on psychological ownership. Pierce et al. (2009) explored the influence of five characteristics in the work characteristics model on psychological ownership. And Mayhew et al. (2007) verified the positive impact about psychological ownership on job satisfaction. The "sense of ownership" inherent in psychological ownership at work will generate the sense of responsibility for work, which will enhance employees' work happiness (Liu, 2018). Based on above research, the study proposes the following hypotheses:

H2: The position competence of service staff will positively affect their psychological ownership.

H3: The psychological ownership of staff in the service industry will positively affect work happiness.

H4: Psychological ownership plays an intermediary role between position competence and work happiness.

Relevant studies on POS show that it is related to psychological ownership closely, and better organizational support is conducive to employees' work happiness (Wang et al., 2018). Wen et al. (2018) verified that POS moderates the relationship between work happiness and emotional labor. Based on those research, this study proposes the hypothesis:

H5: Perceived organizational support moderate the relationship between Position competence and psychological ownership.

Based on these studies, this research believes that service industry employees' position competence positive impact on work happiness, that psychological ownership plays an important mediating role, and POS plays an important moderating role in the relationship. Accordingly, the research framework is designed in figure 1.

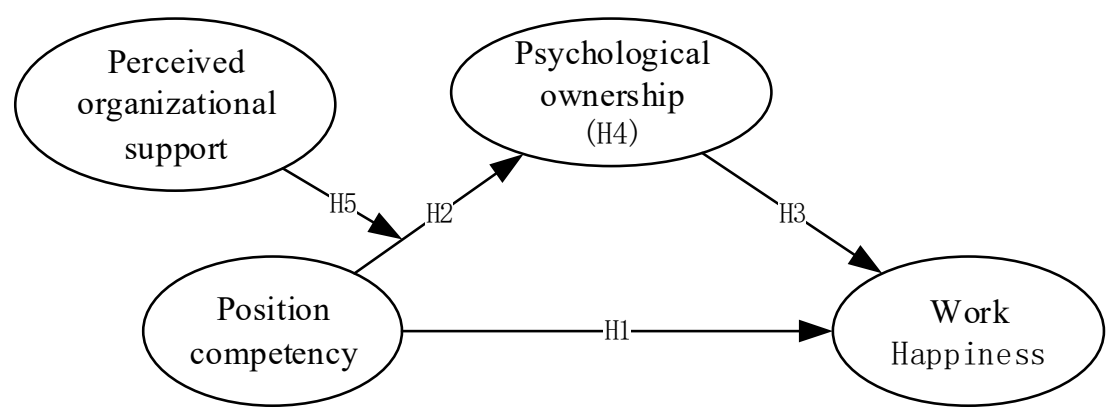

Figure 1. The research framework

\subsection{Questionnaire}

This study collects the information by questionnaire survey. And the questionnaire include personal background information, Position competence scale, psychological ownership scale, perceived organizational support scale and work happiness scale. Likert's five-point scale was used for the questions in the scale. Those are strongly disagreement (1), disagreement (2), moderate (3), agreement (4), strongly agreement (5). 
The Position competence scale is designed by Zhu et al. (2014) which includes 9 items. The Psychological Ownership Scale used the scale designed by Dyne and Pierce (2004) which includes 7 items. The work happiness Scale reference the PWB scale designed by Abbott et al. (2006), which includes 5 dimensions. There are 22 items in total. The perceived organizational support adopted the simplified version of the scale designed by Eisenberger et al. (1986), which includes 5 items.

\subsection{Sampling and Samples}

\subsubsection{Sampling Method}

The sample in this research is selected from personnel of service industry. In the study, According to the historical statistical yearbook data proportion, employees of telecommunications services, financial service, tourism service and education service enterprises with a large number of personnel were selected as respondents. To ensure operability and representativeness of the samples, quota sampling method was adopted to select about 240 people as samples (Xu, 2011).

In the first stage, the whole china is divided into three levels of sampling: western region, central region and eastern region. According to the division of national policies, the eastern part of China includes Liaoning province, Hebei province, Beijing, Tianjin, Shandong province, Jiangsu province, Shanghai, Zhejiang provinces, Fujian provinces, Guangdong provinces and Hainan provinces. The east includes 11 provinces and is the most economically and socially developed region in China. The central belt, which includes Heilongjiang province, Jilin province, Shanxi province, Anhui province, Henan province, Hubei province, Hunan province and Jiangxi provinces, there are 8 provinces where is better than the western belt in general, but not as good as the eastern coastal zone. The western economic zone covers 12 provinces, including Guangxi province, Shaanxi province, Gansu province, Ningxia, Qinghai province, Xinjiang, Chongqing, Sichuan province, Yunnan province, Guizhou province, Tibet and Inner Mongolia (National Bureau of Statistics, 2013).

In the second stage, a sampling box was set and two provinces were randomly selected from three regions. Although the economies of the eastern, central and western regions and the economic development of the provinces within each region are different, the problems in this study are not considered. At the same time, considering that too many provinces will result in too scattered personnel samples and too high survey costs, 2 provinces will be selected for each region. In this study, when extracting specific provinces in each region, a quota sampling method was adopted to number the provinces in the region in advance and generate random numbers to extract specific provinces. Using this simple sampling method, a total of 6 sample provinces were selected in this stage.

In the third stage, for each sample province, find the information of service participants from the social security department and establish a sampling box. In China, the existing legal system stipulates that all enterprises must pay social insurance for their employees, and each province has a "Provincial Department of Human Resources and Social Security" responsible for the unified management of the province's social insurance personnel, and has a social security data database. This study conducted quota sampling on the basis of the information database of social security participants in the service industry after desensitization in each province. The research adopts the method of isometric sampling to sort the people in the information database according to their name, calculate the distance with "total number of people in the database/sample size", and generate random numbers as the starting point for isometric sampling. And then specific service industry employees were randomly selected from the four industries in the sample province.

\subsubsection{Sample Size Allocation}

According to the provincial sampling in the second stage, two provinces were selected from the eastern, western and central regions respectively. The sample provinces are Shandong, Hubei, Jilin, Guangdong, Gansu, and Yunnan. The sample size of service industry employees in each province is determined on the basis of the number of employees in 6 provinces and 4 industries at the end of 2018. Considering the statistical data of the four industries at the end of 2018 (National Statistical Yearbook, 2018), the sample size is evenly distributed. Although the selected samples are located in different provinces and the specific industries engaged in services are also different, this study believes that for the hypothesis to be tested in the study, these sample differences will not affect the final results. Therefore, isometric sampling was adopted in this study. Isometric sampling, also known as systematic sampling, is a sampling method that first arranges the units in the population in a certain order, determines the selection interval according to the sample size requirements, then randomly determines the starting point, and extracts a unit at a certain interval.

Because this study includes 4 potential variables (Position competence, Perceived Organizational Support, 
Psychological Ownership, Work happiness) and 8 observation variables, combined with the number of variables $(8+4=12)$, the sample size of this study is about $240(12 * 20=240)$ (Thompson, 2000). Considering that part of invalid questionnaires need to be deleted to ensure the number of valid samples (Xu, 2011), 360 questionnaires were issued in the formal survey plan. In this study, 360 questionnaires were distributed in 6 provinces and 4 industries. Among them, 60(360/6) people are selected for each province and $90(360 / 4)$ people are selected for each industry, that is, 15 people (60/4) are selected for each industry in each province. For specific sampling, the telecommunications industry personnel in each province shall be numbered successively from 1 to $\mathrm{N}$, and the sampling distance $\mathrm{K}=\mathrm{N} / \mathrm{n}$ shall be calculated. Then select a random number $\mathrm{k} 1$ from $1 \sim \mathrm{K}$ as the first unit of the sample, then take $\mathrm{k} 1+\mathrm{K}, \mathrm{k} 1+2 \mathrm{~K}$...... Until you have 15 people. According to this method, 15 people were selected from financial, tourism and education industries in the province (Zhu, 2018).

\subsubsection{Matching Survey}

Respondents may receive both cause-dimension and result-dimension measurements, resulting in common-method variance for the results (Vecchio, 1982). To ensure the accuracy and validity of measured variables, the method of paired survey was used. Because the survey of position competence cannot only refer to the individual self-evaluation of employees, the supervisor should assess the position competence of respondents and then make a weighted calculation. So paired sampling is needed (Xu, 2011). Since the service industry personnel are randomly selected, it is impossible to set the matching ratio between supervisors and personnel in advance. The specific implementation method is to find out their supervisors in pairs and conduct a questionnaire survey to their supervisors. Due to coincidence, two personnel will have the same supervisor in the investigation. Then average the data collected from the survey of supervisors and research objects, and obtain the survey and analysis data of Position competence.

\subsubsection{Questionnaire Distribution}

As for the research tool- questionnaire, this study has been revised and compiled into the first draft of the questionnaire based on the references and reference scale and the actual situation of Chinese service industry personnel. A pre-survey was conducted and 50 questionnaires were expected to be issued (Xu, 2011). Then, the Corrected Item-Total Correlation (CITC) analysis, reliability analysis was conducted to form a formal questionnaire and conduct a formal survey.

This research use Amos as the main research analysis software, verify the fitting about SEM (Structural Equation Model). The SEM has strict requirements on the sample size, that too big and too small are not appropriate. This is because the SEM in the adaptation degree test, as absolute adaptation index card party affected by the size of the sample size, sample size is easy to make more chi-square value reached significant level $(p<0.05)$, shows that model should be rejected.

How many samples are most appropriate in SEM analysis? It is generally believed that structural equation model of sample size about 200 to 500 , the best sample proportion and the number of observed variables should be about 10 to 1 (Schumacker \& Lomax, 1996).

In the part of data collection and questionnaire distribution, with the help of internet video, the personal administered questionnaire survey is used to distribute and collect the questionnaire (Zhu, 2018). Because the questionnaire can not only be recovered in a short time, but also can be immediately clarified in person when the interviewee has questions, which helps to improve the recovery rate and accuracy rate of the questionnaire. After the questionnaire was returned, the data of the questionnaire was first screened. Invalid questionnaires were eliminated according to criteria such as whether there were a lot of missing data and too many repeated answers such as the same answer for more than 10 consecutive questions (Groves, Cialdini \& Couper, 1992).

Through the strict and standard data collection and verification process, the effective rate of this questionnaire is high. However, Nonresponse bias may still have a negative impact on sample quality and study reliability and validity (Emory \& Cooper, 1991). Therefore, after the completion of the survey and receipt of the data, this study also divided the collected questionnaires equally into two groups according to the order of time, and compared whether the two groups had significant differences in the basic information of the questionnaires (Armstrong \& Overton, 1977). The results show that the influence of nonresponse bias on this survey is not obvious and can be ignored.

For the valid data after filtering, statistical analysis tools such as SPSS and AMOS were used to conduct descriptive statistical analysis, correlation analysis, CFA (confirmatory factor analysis), regression analysis, etc. 


\section{Results}

\subsection{Descriptive Statistical Analysis}

In this study, 360 questionnaires were sent out to service personnel, and 342 questionnaires were returned. Because of the paired survey design, 325 supervisors were surveyed. The reason why 342 supervisors were not investigated is that in the sample, two supervisors were selected as the same supervisor. This is when a supervisor has to grade two subordinates. 342 paired questionnaires were distributed to 325 supervisors, and 328 valid paired questionnaires were recovered, covering the supervisor evaluation and personal evaluation of the Position competence of 328 respondents. The effective rate was $91.7 \%$. The reason why 14 questionnaires were deleted is that the employees who were selected were the top executives of the enterprise, and some supervisors could not cooperate with the investigation. Among the 328 people being investigated, 138 are men, accounting for $42.1 \%$ of the total number, 190 are women, accounting for $57.9 \%$ of the total number, and women account for slightly more than men. The age distribution was $18-30$ years old, accounting for $55.2 \%$. Education degree is mainly for undergraduates, with 154 students accounting for $47 \%$. The position level of general staff is the most, accounting for $51.2 \%$. The Length of service was from 1 to 10 years, accounting for $54.9 \%$. The enterprise size is mainly 11-200, accounting for 43.6\%. The distribution of samples in this study is basically in line with the status quo of service personnel in the service industry.

Table1. Basic data analysis of the questionnaire

\begin{tabular}{|c|c|c|c|c|}
\hline Personal Background & Information & Category & Sample size & Percent $(\%)$ \\
\hline \multirow{2}{*}{\multicolumn{2}{|c|}{ Gender }} & Male & 138 & 42.1 \\
\hline & & Female & 190 & 57.9 \\
\hline \multirow{4}{*}{ Age } & & 18 to 30 & 181 & 55.2 \\
\hline & & 31 to 44 & 106 & 32.3 \\
\hline & & 45 to 59 & 40 & 12.2 \\
\hline & & $>60$ & 1 & 0.3 \\
\hline \multirow{4}{*}{ Education } & & High school graduate and below & 47 & 14.3 \\
\hline & & College graduate & 95 & 29 \\
\hline & & Bachelor degree & 154 & 47 \\
\hline & & Master degree and above & 32 & 9.8 \\
\hline \multirow{4}{*}{ Position } & & General staff & 168 & 51.2 \\
\hline & & First-line managers & 77 & 23.5 \\
\hline & & Middle managers & 54 & 16.5 \\
\hline & & Top managers & 29 & 8.8 \\
\hline \multirow{3}{*}{\multicolumn{2}{|c|}{ Length of Service }} & Less than 1 year & 101 & 30.8 \\
\hline & & Between one and ten years & 180 & 54.9 \\
\hline & & 11 years or above & 47 & 14.3 \\
\hline \multirow[t]{4}{*}{ Enterprise Size } & & $<10$ & 42 & 12.8 \\
\hline & & 11 to 200 & 143 & 43.6 \\
\hline & & 201 to 500 & 58 & 17.7 \\
\hline & & $>500$ & 85 & 25.9 \\
\hline
\end{tabular}

Data source: Analysis of this study.

With regard to the distribution of samples among different dimensions, this study includes 4 variables. The results show that the mean value of the Position competence variable is 3.947, the standard deviation is 0.922 , the minimum value is 1 , and the maximum value is 5 , which show that most of the respondents agree with the Position competence. The variable of work happiness refers to 3.690 , the standard deviation is 0.880 , the minimum value is 1 , and the maximum value is 5 , indicating that most respondents have a high degree of recognition of work happiness, that is, respondents generally have a high degree of work happiness. In the survey results of the remaining variables, the mean value are all greater than 3.4. This indicates that respondents have a high level in these dimensions. 


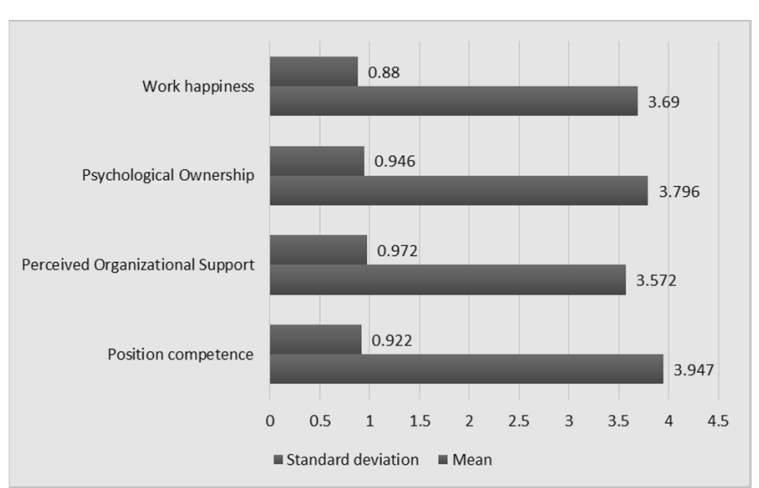

Figure 2. Descriptive statistics of each dimension

Data source: Analysis of this study. The criteria: Very low (1-1.8), Low (1.81-2.6), Moderate (2.61-3.4), High (3.41-4.2), Very high (4.21-5).

\subsection{Reliability Analysis}

The variables in this study are all ordered variables. The appropriate index for the reliability test is Cronbach's $\alpha$. When Cronbach's $\alpha$ is more than 0.7, it is believed the questionnaires has a good consistency. The Cronbach's $\alpha$ results of four variables are $0.949,0.917,0.933$ and 0.975 , which are all above 0.9 , indicating the 4 variables have good reliability.

Table 3. Reliability analysis results

\begin{tabular}{lcc}
\hline Variables & Cronbach's $\alpha$ & Number of Item \\
\hline Position competence & 0.949 & 9 \\
Perceived Organizational Support & 0.917 & 5 \\
Psychological Ownership & 0.933 & 7 \\
Work happiness & 0.975 & 22 \\
\hline
\end{tabular}

Data source: Analysis of this study.

\subsection{Confirmatory Factor Analysis}

Table 4. Fitting indexes about SEM

\begin{tabular}{ccccccrc}
\hline$\chi^{2} / \mathrm{df}$ & GFI & AGFI & NFI & IFI & CFI & SRMR & RMSEA \\
\hline 1.508 & 0.866 & 0.896 & 0.946 & 0.908 & 0.917 & 0.046 & 0.071 \\
\hline
\end{tabular}

Data source: Analysis of this study.

The fitting indexes about this model are shown in table $4 . \chi^{2} / \mathrm{df}$ is 1.508 , less than 2 , indicating that the model fitting is good. GFI value is 0.866 , AGFI value is 0.896 , NFI value is 0.946 , IFI value is 0.908 , CFI value is 0.917 . The indexes of this model are all above 0.80 , means that the model fitting is acceptable. And SRMR value is 0.046 , less than 0.5 , RMSEA value is 0.071 , less than 0.08 , indicates the well model fitness.

\subsection{Correlation Analysis}

Table 5. Correlation analysis results

\begin{tabular}{|c|c|c|c|c|}
\hline Dimension & 1 & 2 & 3 & 4 \\
\hline 1. Position competence & 1 & & & \\
\hline $\begin{array}{l}\text { 2. Perceived } \\
\text { Organizational Support }\end{array}$ & $0.654 * *$ & 1 & & \\
\hline 3. Psychological Ownership & $0.841 * *$ & $0.798 * *$ & 1 & \\
\hline 4. Work happiness & $0.765 * *$ & $0.742 * *$ & $0.696 * *$ & 1 \\
\hline
\end{tabular}

Note. ${ }^{* *}$ means significant at $1 \%$ level. 
As the analysis result shown in Table 5, the correlation coefficient between position competence and psychological ownership is 0.841 , the $\mathrm{P}$ value less than 0.01 , means that at 0.01 significance level positive relationship between position competence and psychological ownership is significant. Correlation coefficient between position competence and perceived organizational support is 0.654 , and $\mathrm{P}$ value is 0.000 , less than 0.01 , means that at the significance level of $1 \%$, positive relationship between position competence and perceived organizational support is significant. As can be seen from other analogies, significant relationships exist in all the variables.

\subsection{Structural Equation Model Analysis}

\subsubsection{Results of Path Structure Diagram}

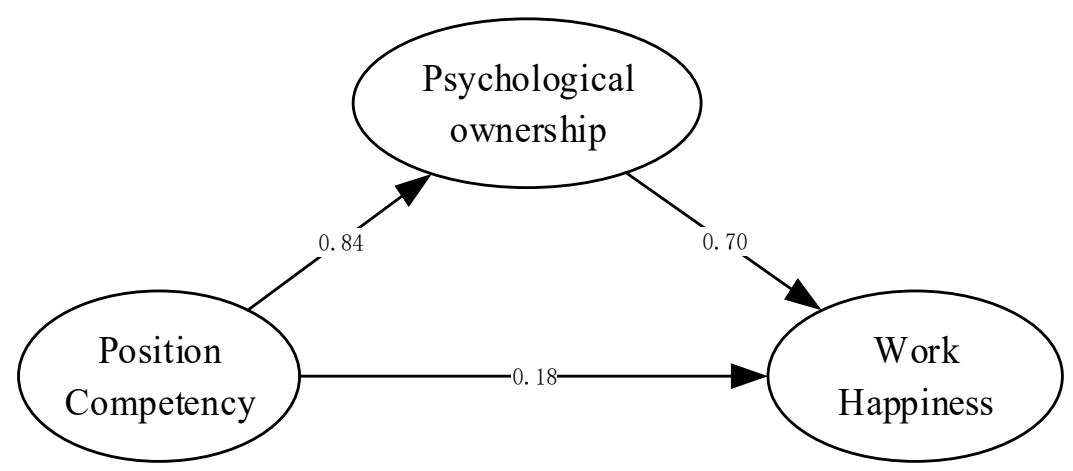

Figure3. Path result diagram

\subsubsection{Path Significance Results and Mediation Effect Test}

Table 6. Path coefficient results of structural equations

\begin{tabular}{|c|c|c|c|c|c|}
\hline Path & $\begin{array}{l}\text { Standardization } \\
\text { coefficient }\end{array}$ & $\begin{array}{l}\text { Unstandardized } \\
\text { coefficient }\end{array}$ & Standard error & $\mathrm{T}$ & $\mathrm{P}$ \\
\hline $\begin{array}{l}\text { Psychological ownership <--- } \\
\text { Position competence }\end{array}$ & 0.841 & 0.8 & 0.057 & 14.112 & $* * *$ \\
\hline $\begin{array}{l}\text { Work happiness <--- } \\
\text { Position competence }\end{array}$ & 0.18 & 0.085 & 0.063 & 1.338 & 0.096 \\
\hline $\begin{array}{l}\text { Work happiness <--- } \\
\text { Psychological ownership }\end{array}$ & 0.696 & 0.645 & 0.059 & 10.877 & $* * *$ \\
\hline
\end{tabular}

Data source: Analysis of this study.

The path coefficients result of the structural equations as shown in Table 6. Standardization coefficient about psychological ownership < --- Position competence is 0.841 , unstandardized coefficient is 0.8 , standard error is 0.057 , value of $\mathrm{T}$ is 14.112 , and value of $\mathrm{P}$ is smaller than $0.001(* * *)$, means that path from position competence to psychological ownership is significant, and between position competence and psychological ownership it is a significant positive relationship, which verifies $\mathrm{H} 2$. And then the similar path analysis show that psychological ownership to work happiness is significant positive relationship, which verifies H3.

Standardization coefficient of work happiness <-- Position competence is 0.18 , unstandardized coefficient is 0.085, value of $\mathrm{P}$ is 0.096 , less than 0.1 , which means that path from Position competence to work happiness is relatively significant.

The estimates of $\mathrm{a}, \mathrm{b}, \mathrm{c}$ and $\mathrm{c}$ 'and their corresponding standard errors can be easily obtained by using structural equation software, and significance tests can be conducted and confidence intervals of path coefficients can be constructed (MacKinnon, 2008; Preacher \& Hayes, 2008). Total effect c is equal to ab plus c'. That is,

$$
\mathrm{c}=\mathrm{ab}+\mathrm{c},
$$

$\mathrm{C}$ is the total effect, $\mathrm{c}^{\prime}$ is the direct effect after considering the intermediate effect, and $\mathrm{ab}$ is the intermediate effect or indirect effect. According to Wen's research results, as the path coefficient of $c^{\prime}\left(c^{\prime}=0.18\right)$ is significant (the path coefficient of work happiness $<-$ - Position competence is significant [P value is $0.096<0.10]$ ), it is a 
partial mediating effect.

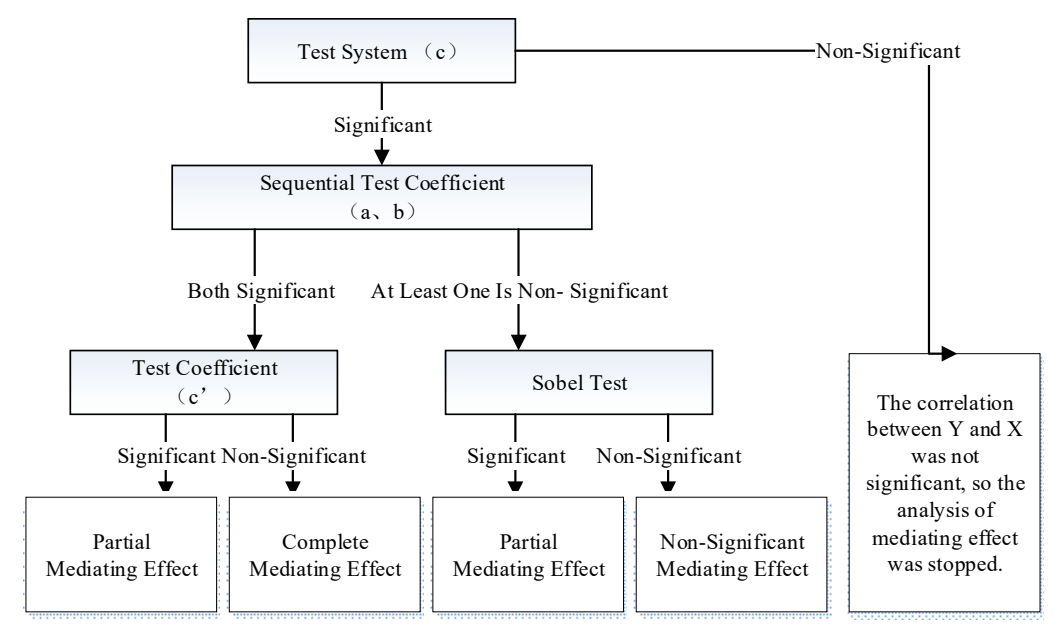

Figure 4. Mediation effect test procedure

Psychological ownership plays a significant and partial mediating role in the relationship between Position competence and work happiness $(\beta a=0.841, p<0.001, \beta b=0.096, p<0.001)$, which verifies H4. The Mediate effect value is $a b=$

$0.841 * 0.696=0.585$.

\section{6 Regression Analysis}

In this study, two step regression analysis method was used to verify the moderate effect of POS according to research of Wen (2015). In the first step, conduct multiple linear regression analysis with psychological ownership as dependent variable, position competence and POS as independent variables. In the second step, conduct multiple linear regression analysis, psychological ownership as dependent variable, position competence, POS and position competence multiplied by POS as independent variables.

The first step of the regression results, as shown in model lof table7, $\mathrm{R}^{2}$ is 0.74 , position competence of regression coefficient is 0.439 , the $\mathrm{T}$ value is 11.917 , $\mathrm{P}$ value is 0.000 , less than 0.01 . That means relationship between position competence and psychological ownership is significant positive. This also verifies hypothesis $\mathrm{H} 2$.

The second step of the regression analysis results, as shown in model 2 of table7, $\mathrm{R}^{2}$ is $0.753, \mathrm{R}^{2}$ of model 2 is higher than model 1 . The regression coefficient of position competence multiplied by POS is -0.026 , the value of $\mathrm{T}$ is- 0.862 , the value of $\mathrm{P}$ is 0.000 , indicating that the interaction between position competence and perceived organizational support (position competence * POS) is significant, and the POS has a negative significant moderate effect. This also verifies hypothesis H5.

Table 7. The analysis about moderating effect of POS

\begin{tabular}{|c|c|c|c|c|c|c|}
\hline \multicolumn{4}{|c|}{ The Dependent Variable } & \multicolumn{3}{|c|}{ Psychological Ownership } \\
\hline \multirow[t]{2}{*}{ Variables } & \multicolumn{3}{|c|}{ Model 1} & \multicolumn{3}{|c|}{ Model 2} \\
\hline & $\beta$ & $\mathrm{t}$ & VIF & $\beta$ & $\mathrm{t}$ & VIF \\
\hline Position competence & 0.439 & $11.917^{* * *}$ & 2.483 & 0.427 & $10.845^{* * *}$ & 2.843 \\
\hline Perceived Organizational Support & 0.511 & $13.882 * * *$ & 2.467 & 0.514 & $13.901 * * *$ & 2.467 \\
\hline \multicolumn{4}{|l|}{ Position competence * } & -0.026 & $-0.862 * * *$ & 1.407 \\
\hline \multicolumn{7}{|l|}{ Perceived Organizational Support } \\
\hline $\mathrm{F}$ & \multicolumn{3}{|c|}{$113.715^{* * *}$} & \multicolumn{3}{|c|}{$107.691 * * *$} \\
\hline $\mathrm{R} 2$ & \multicolumn{2}{|c|}{0.74} & & \multicolumn{3}{|c|}{0.753} \\
\hline adj-R2 & \multicolumn{2}{|r|}{0.734} & & \multicolumn{3}{|c|}{0.746} \\
\hline Overall model & \multicolumn{2}{|r|}{0.000} & & \multicolumn{3}{|c|}{0.000} \\
\hline
\end{tabular}

Note. ${ }^{* * *}$ means $\mathrm{p}$ value less than 0.01 . 


\subsection{Hypothesis Verification Results}

Based on the regression analysis and SEM analysis of the questionnaire data, I obtained the verification results of the research hypothesis. Here, the verification results of the research hypothesis are summarized and sorted out, as shown in Table 8 below.

Table 8. Results of hypothesis verification

\begin{tabular}{clc}
\hline Research hypothesis & Test Results & Instructions \\
\hline H1 & Support & It is verified by SEM analysis. \\
H2 & Support & It is verified by SEM analysis and regression analysis. \\
H3 & Support & It is verified by SEM analysis. \\
H4 & Support & It is verified by SEM analysis. \\
H5 & Support & It is verified by regression analysis. \\
\hline
\end{tabular}

Data source: Analysis of this study.

\section{Conclusions and Discussion}

\subsection{Research Conclusions}

In this paper I studies the relationships among position competence, psychological ownership, POS and work happiness of service personnel and draws the following conclusions:

Position competence affect their psychological ownership positively, the higher position competence, the stronger their psychological ownership; psychological ownership positively affect work happiness. The higher the degree of psychological ownership, the stronger the work happiness they feel;

Position competence positively affect their work happiness, the stronger the Position competence, the higher their work happiness, and Position competence have a positive impact on their work happiness through the mediation role of psychological ownership.

POS negatively moderates the relationship of Position competence and psychological ownership. As perceived organizational support increased, the effect of position competence on psychological ownership decreased. This is because perceived organizational support positively affect psychological ownership.

\subsection{Research Implication}

Theoretically, the empirical data of this study confirmed the important value of position competence of service industry employees in promoting work happiness. This paper explores the possible mediating effect of psychological ownership on Position competence and work happiness, and puts forward and verifies its moderating effect on Position competence and psychological ownership based on existing research results on perceived organizational support. These results not only reveal the "black box" of the function mechanism between Position competence and work happiness of service industry employees from the cognitive level, but also further verify and expand the theory of work happiness of positive organizational behavior based on the theme of work happiness.

In practice, this paper further enriches the research on position competence and work happiness, and verifies the importance of psychological ownership and POS. It offers a new way of thinking about service industry how to get employees suitable for their positions, improve job performance and improve employee relations. Service enterprises can enhance employees' psychological ownership and work happiness by actively improving their position competence. Psychological ownership can also be enhanced by positively influencing employees' perceived organizational support. The result of this is very beneficial not only to the improvement of the job performance of service enterprises, but also to the selection, use, education, retention, motivation and work happiness of service employees.

\subsection{Countermeasures and Suggestions}

5.3.1 Change Ideas and Attach Importance to Individual Position Competence and Perceived Organizational Support

Employees are important human resources for service organizations. Therefore, improving the position 
competence of human resources, retaining and playing the value of human resources are the prerequisite and key factors to help enterprises improve work happiness. Youssef-Morgan and Luthans (2013) proposed that psychological capital and perceived organizational support are the necessary conditions for employees to achieve high performance. Organizations and managers need to change management philosophy, put individual work happiness in the first place, improve employees' position competence, provide more scientific and perfect organizational support, and let employees feel and benefit from it. This is the key to improve employees' work happiness, and also the condition for the long-term development of the organization.

Service enterprises should put employees' work happiness in the first place, and attach importance to individual position competence and physical and mental health. This is the primary condition affecting individual work happiness, the fundamental condition for the long-term development of enterprises, and the prerequisite for psychological capital. In addition, pay attention to the importance of organizational support, so that employees can feel more care and support from the organization, managers and colleagues, establish a scientific and reasonable training and incentive system and mechanism, and play a more important role from the perspective of internal and external motivation.

5.3.2 Improve Individual Positive Traits Such as Psychological Ownership from the Perspective of Intrinsic Motivation

Positive individual traits such as psychological ownership plays a critical role in employee personal growth and organizational development, and they can change with the work environment, the people they come into contact with, and the events they experience.

Firstly, enterprise focuses on individual positive attitude and allows participants to perceive them in the selection process. When a manager mentions words related to an individual's positive attitude during an interview, employees can feel that this is the positive expectation of the organization for employees, and they will strengthen the cultivation and improvement of their positive traits in the future work.

Secondly, enterprise improves the psychological ownership of employees in the training process. Enterprise provides opportunities for further study and learning from skills and majors to improve the ability of concentration, promote employees' personal development, the improvement of individual work ability help to promote the formation of psychological ownership, stimulate innovation and work enthusiasm. Leaders should establish an ownership culture within the organization, strengthen the people-oriented management concept, build a reasonable internal communication mechanism, and enhance the relationship between employees and the organization and the trust between employees. Leaders should grant formal ownership to key employees in the organization. Employees can participate in organizational management, have the right to influence the development of the organization, stimulate their sense of responsibility, and improve their psychological ownership. Leaders should enable non-key employees to obtain informal rights. For example, by sharing organizational information, publicizing internal strategies and strengthening internal information communication, leaders should actively convey the mission, vision and values of the organization, deepen employees' cognition of the organization and enhance their sense of belonging, which in turn increases work happiness.

\subsubsection{Enhance Organizational Support from the Perspective of Extrinsic Motivation}

Perceived organizational support is to provide sufficient policy, material, spiritual and technical support for employees in the process of work from the perspective of external incentive, which plays a key role in stimulating employees' work involvement, thus increasing their work happiness. It can be analyzed from three aspects of organizational strategy planning, organizational system and managers. One is to focus on long-term development and develop a health promotion plan for employees. Second is to establish regular rotation system to improve work involvement and colleagues support. Third is to improve management level, promote organizational support and colleagues support. Managers need to improve their empathy ability from the perspective of employees, pay attention to employees' development expectations and needs, and provide a platform and space for personal development. From the life to give employees more care and care, pay attention to the family life of employees, timely understand the difficulties and problems encountered. Technical guidance and encouragement at work can stimulate employees' enthusiasm for work and sense of belonging to the organization, improve work happiness.

\subsection{Research Limitation and Future Suggestion}

The study was conducted only in China's service sector. Although the sampling has been carefully designed in this study, due to the difficulty in issuing questionnaires in the survey, the questionnaire survey in this study was only carried out in China and its coverage was not extensive enough, leading to the limitation of the research 
results and inference. This will reduce the representativeness of the research results. Subsequently, the coverage and number of samples should be expanded to increase the representativeness of the research.

\section{Acknowledgments}

This work was supported by Shandong Social Science Planning Research Project (No. 15CQSJ08), Social Science Planning research Project of Shandong Province (No. 18CSJJ09) and Shandong Province Higher Education Reform key project (No. Z2018S040).

\section{References}

Abbott, R. A., Ploubidis, G. B., \& Huppert, F. A. (2006). Psychometric evaluation and predictive validity of riff's psychological well-being items in a UK birth cohort sample of women. Health and Quality of Life Outcomes, 4(1), 76. https://doi.org/10.1186/1477-7525-4-76

Abraído-Lanza, F. (1997). Latinas with arthritis: effects of illness, role identity, and competence on psychological well-being. American Journal of Community Psychology, 25(5), 601-627. https://doi.org/10.1023/A:1024682800238

Armstrong, J. S., \& Overton, T. S. (1977). Estimating non response bias mail surveys. Journal of Marketing Research, 14, 396-402. https://doi.org/10.2307/3150783

Avey, J. B., Avolio, B. J., \& Crossley, C. D. (2009). Psychological ownership: theoretical extensions, measurement and relation to work outcomes. Journal of Organizational Behavior, 30(2), 173-191. https://doi.org/10.1002/job.583

Beggan, J. K. (1992). On the social nature of nonsocial perception: the mere ownership effect. Journal of Personality and Social Psychology, 62(2), 229-237. https://doi.org/10.1037/0022-3514.62.2.229

Crosby, R. K., \& Petrosko, J. M. (1990). Teacher and student perceptions of work attitudes in trade and industrial education. Journal of Industrial Teacher Education, 28, 41-51.

Diener, E. (2000). Subjective well-being: The science of happiness and a proposal for a national index. American Psychologist, 55(1), 34. https://doi.org/10.1037/0003-066X.55.1.34

Dyne, L. V., \& Pierce, J. L. (2004). Psychological ownership and feelings of possession: three field studies predicting employee attitudes and organizational citizenship behavior. Journal of Organizational Behavior, 25(4), 439-459. https://doi.org/10.2307/4093721

Eisenberger, R. (1986) . Perceived organizational support. Journal of Applied Psychology, 71,500-507. https://doi.org/10.1037/0021-9010.71.3.500

Emory, J., \& Cooper, E. (1991). Workplace literacy instruction and evaluation. American Reading Forum Online Yearbook, X1, 11-26. https://doi.org/10.1055/s-2006-957022

Gorsuch, R. L., \& Ortberg, J. (1983). Moral obligation and attitudes: their relation to behavioral intentions. Journal of Personality and Social Psychology, 44(5), 1025-1028. https://doi.org/10.1037/0022-3514.44.5.1025

Groves, R. M., Cialdini, R. B., \& Couper, M. P. (1992). Understanding the decision to participate in a survey. Public Opinion Quarterly, 56,475-495. https://doi.org/10.1086/269338

Heponiemi, T., \& Aalto, A. M. (2014). Work-related stress, job resources, and well-being among psychiatrists and other medical specialists in Finland. Psychiatric Services, 65(6), 796-801. https://doi.org/10.1176/appi.ps.201300200

Jackson, N. (2003). Learning and teaching support network: enhancing teaching and learning through brokerage. Engaging \& Changing Higher Education Through Brokerage.

Kuijpers, C. T. (2006). Career competencies for the modern career. Journal of Career Development, 32(4), 303-319. https://doi.org/10.1177/0894845305283006

Liu, B., \& Liu, P. Q. (2018). Research on the impact of authorized leadership on employee work happiness based on chain mediation effect. Leadership Science, 17, 29-32. https://doi.org/10.3969/j.issn.1003-2606.2018.17.010

Luthans, F. (2002). The need for and meaning of positive organizational behavior. Journal of Organizational Behavior, 23(6), 695-706. https://doi.org/10.1002/job.165

Mayhew, M. G., Ashkanasy, N. M., Bramble, T., \& Gardner, J. (2007). A study of the antecedents and 
consequences of psychological ownership in organizational settings. The Journal of Social Psychology, 147(5), 477-500. https://doi.org/10.3200/SOCP.147.5.477-500

McClelland, D. C. (1973). Testing for competence rather than for "intelligence". American Psychologist, 28(1), 1-14. https://doi.org/10.1037/h0034092

Meneghel, I., Salanova, M., \& Martínez, I. M. (2016). Feeling good makes us stronger: how team resilience mediates the effect of positive emotions on team performance. Journal of Happiness Studies, 17(1), 239-255. https://doi.org/10.1007/s10902-014-9592-6

Pan, X. F, Qin, Q.W, Zhang, Y. H. et al. (2012). The influence of Organizational Psychological Ownership and self-esteem on positive organizational behavior. Journal of Psychological Science, 35(3), 718-724. https://www.psysci.org/EN/Y2012/V35/I3/718

Park, S. A., \& Ahn, S. H. (2015). Relation of compassionate competence to burnout, job stress, turnover intention, job satisfaction and organizational commitment for oncology nurses in Korea. Asian Pacific Journal of Cancer Prevention APJCP, 16(13), 5463-9. https://doi.org/10.7314/APJCP.2015.16.13.5463

Parker, A., \& Gellatly, A. (1997). Moveable cues: a practical method for reducing context-dependent forgetting. $\begin{array}{llll}\text { Applied } \quad \text { Cognitive } & \text { Psychology, } & 11(2), & 163-173 .\end{array}$ https://doi.org/10.1002/(SICI)1099-0720(199704)11:23.0.CO;2-1

Pierce, J. D., \& Dewsbury, D. A. (1991). Female preferences for unmated versus mated males in two species of voles (Microtus Ochrogaster and Microtus Montanus). Journal of Comparative Psychology, 105(2), 165-171. https://doi.org/10.1037/0735-7036.105.2.165

Pierce, J. L., Jussila, I., \& Cummings, A. (2009). Psychological ownership within the job design context: revision of the job characteristics model. Journal of Organizational Behavior, 30(4), 477-496. https://doi.org/10.1002/job.550

Pierce, J. L., Kostova, T., \& Dirks, K. T. (2001). Toward a theory of psychological ownership in organizations. Academy of Management Review, 26(2), 298. https://doi.org/10.5465/AMR.2001.4378028

Pierce, J. L., Kostova, T., \& Dirks, K. T. (2003). The state of psychological ownership: integrating and extending a century of research. Review of General Psychology, 7(1), 84-107. https://doi.org/10.1037//1089-2680.7.1.84

Pierce, J. L., Rubenfeld, S. A., \& Morgan, S. (1991). Employee ownership: a conceptual model of process and effects. The Academy of Management Review, 16(1), 121-144.

Sandberg, J. (2000). Understanding human competence at work: an interpretative approach. The Academy of Management Journal, 43(1), 9-25. https://doi.org/ 10.5465/1556383

Schumacker, R. E., \& Lomax, R. G. (1996). A Beginner's Guide to Structural Equation Modeling. Mahwah, NJ: Erlbaum. https://doi.org/10.1198/tech.2005.s328

Spencer, L. M., \& Spencer, S. M. (1993). Competence at work: models for superior performance. New York: John Wiley and sons.

Tai, W. (2016). A Company: Research on Personality Traits of Life Insurance Business Personnel (Doctoral dissertation, Jinan University, 2016). Dissertation Abstracts International, 27, 154A. https://doi.org/CNKI:CDMD:2.1016.734905

Thompson, B. (2000). Ten Commandments of Structural Equation Modeling. In L. G. Grimm \& P. R. Yarnold (Eds.), Reading and understanding more multivariate statistics. Washington, DC: American Psychological Association.

Tomietto, M. P., Eleonora, S. R., \& Maricchio, R. C. (2019). Work engagement and perceived work ability: An evidence-based model to enhance nurses' well-being. Journal of advanced nursing, 75(9), 1933-1942. https://doi.org/10.1111/jan.13981

Vecchio, R. P. (1982). The Contingent-Noncontingent Compensation Controversy: An Attempt at a Resolution. Human Relations, 35, 449-462. https://doi.org/10.1177/001872678203500602

Wagner, S. H., Parker, C. P., \& Christiansen, N. D. (2003). Employees that think and act like owners: effects of ownership beliefs and behaviors on organizational effectiveness. Personnel Psychology, 56(4), 847-871. https://doi.org/10.1111/j.1744-6570.2003.tb00242.x

Wang, G., Su, Z. Q., Zhang, D. J. (2018). Effects of Competence and Occupational Stress on Occupational 
Well-being among Kindergarten Teachers: The role of Occupational Identity and Job Burnout. $\begin{array}{lllll}\text { Psychological Development } & \text { and } & \text { Education, } & 33 & \text { (5), }\end{array}$ https://doi.org/10.16187/j.cnki.issn1001-4918.2017.05.13

Wen, J., \& Hou, P. P. (2018). Emotion Intelligence and Job Satisfaction of Hotel Frontline Staff: A Study Based on the Dual-stage Moderating Role of Perceived Organizational Support. Nankai Business Review, 21(1), 146-158. https://doi.org/CNKI:SUN:LKGP.0.2018-01-016

Wen, Z. L., Zhang, L., \&Liu, H. Y. (2004). Mediating effect test procedure and its application. Acta Psychological Sinica, 36(5), 614-620. https://doi.org/CNKI:SUN:XLXB.0.2004-05-016

Xu, Y. J. (2011). Social Survey Design and Data Analysis. Chongqing: Chongqing university press.

Yang, Y. P. (2013). Study on the antecedents of online shopping consumer loyalty. (Doctoral dissertation, Southwest University of Finance and Economics).

Youssef-Morgan, C. M., \& Luthans, F. (2013). Positive leadership: meaning and application across cultures. Organizational Dynamics, 42(3), 198-208. https://doi.org/10.1016/j.orgdyn.2013.06.005

Zhu, H. B. (2018). Questionnaire Survey and Statistical Analysis Method: Based on SPSS. Beijing: Publishing House of Electronics Industry.

Zhu, Y. Y., Xia, Z. J., \&Wang, J. C. (2014). Research on the Relationship among Marketing Personnel Competence, Organizational Support and Work Well-being: Based on the Perspective of Manufacturing Servitization. Industrial Engineering and Management, 19(6), 124-132. https://doi.org/10.3969/j.issn.1007-5429.2014.06.020

\section{Copyrights}

Copyright for this article is retained by the author(s), with first publication rights granted to the journal.

This is an open-access article distributed under the terms and conditions of the Creative Commons Attribution license (http://creativecommons.org/licenses/by/4.0/). 